\title{
The 39-week rule and term stillbirth: beneficence, autonomy, and the ethics of the current restrictions on early-term labor induction in the US
}

\author{
James M. Nicholson
}

From Stillbirth Summit 2014

Medina, MN, USA. 19-21 June 2014

The cumulative risk of term stillbirth, i.e., the death of a fetus in utero on or after 37 weeks 0 days of gestation, increases with increasing gestational age throughout the term period (37 weeks 0 days -41 weeks 6 days)[1]. Despite this fact, a rule - called the 39-week rule was established in 2009 that restricts labor induction in the $37^{\text {th }}$ and $38^{\text {th }}$ week of pregnancy (i.e., in the "earlyterm period") unless an accepted/approved "indication" is present (Table 1). [2] The 39-week rule is now a strict clinical guideline that is enforced by professional organizations, governmental agencies and the medical insurance industry[3-5]. The 39-week rule means that a pregnant woman who has an identifiable risk factor for stillbirth but who does not have an accepted "indication" for labor induction has no choice but to wait until at least 39 weeks 0 days before she can be delivered. Unfortunately, the strict application of the 39-week rule has probably led to hundreds early-term stillborn infants in the US over the past few years[6,7].

The purpose of this presentation was to disclose major problems with the development, application and ethics of the 39-week rule. Firstly, the evidentiary foundation of the 39-week rule is composed almost entirely of observational studies (i.e., Level 2 evidence) that contain a variety of serious flaws including confounding by indication, [8-10] confounding by situation, [10-12] selection bias, [13] misclassification bias, [14] incorrect modelling, [8-10] and the use of data from pre-37 week deliveries $[10,15]$ and/or pre-labor cesarean deliveries. $[16,17]$. Secondly, these observational studies report magnitudes of

Correspondence: jnicholson@hmc.psu.edu

Department of Family and Community Medicine, Hershey Medical Center, Pennsylvania State University, Hershey, Pennsylvania, USA
Table 1 Accepted Indications for Labor Induction

\begin{tabular}{l}
\hline Late-term pregnancy $(>41$ weeks 0 days of gestation) \\
Severe fetal growth restriction (fetus not growing, $<5 \%$ ) \\
\hline Rupture of membranes without labor \\
\hline Severe pre-eclampsia (hypertension of pregnancy) \\
\hline Chorio-amnionitis (amniotic fluid infection) \\
\hline Failed antenatal testing (possible fetal compromise) \\
\hline Significant oligohydramnios (AFI $<6)$
\end{tabular}

association between early-term non-indicated labor induction and adverse birth outcomes (as measured in relative risk [RR], odds ratio [OR]) that are not large enough to be used to claim the identification of an underlying "truth" (i.e., that early-term non-indicated labor inductions per se cause adverse birth outcomes). [18] Thirdly, the evidentiary foundation ignores recent higher-quality research that suggests that early-term non-indicated labor induction might provide significant benefits[19-21]. Fourthly, the 39-week rule was created by a process that chose the relatively arbitrary "cutpoint" of 39 weeks 0 days of gestation [22], failed to consider the potential importance of intermediate levels of prenatal risk [23], ignored the opinions and experience of non-academic providers [24], and excluded input from the general public. Fifthly, the 39 -week rule ignores the primary importance of the medical ethical principle of Autonomy [25,26]. Autonomy represents the concept that a patient, given that she has a reasonably good understanding of risk and benefit, has the right to either request or refuse any given reasonable medical therapy. The 39 -week rule prevents a woman from requesting and receiving a non-indicated induction 
of labor in the early-term period of pregnancy. The reason given for this restriction on patient autonomy in the setting of early-term non-indicated labor induction is the application of another medical ethical principle called Beneficence [2]. Beneficence represents the concept that a provider has the obligation to provide a patient with the best treatment(s) available. However, as noted above, it is unclear if the use of labor induction in the absence of an accepted "indication" in the early-term period of pregnancy provides more harm than benefit. The 39-week rule is not supported by the type of evidentiary foundation that is generally needed to restrict patient Autonomy [27,28].

In summary, the 39-week rule is not supported by high-quality evidence, its strict application unjustifiably obstructs patient autonomy, and it may actually cause harm in the form of early-term stillbirth. Because of these problems the 39-week rule should be modified, made optional, or withdrawn. Patients should be able to request and receive early-term labor induction if they believe that such an intervention is in the best interest of themselves and/or their fetus.

Published: 15 April 2015

\section{References}

1. Smith GC: Life-table analysis of the risk of perinatal death at term and post term in singleton pregnancies. Am J Obstet Gynecol 2001, 184(3):489-496.

2. ACOG: ACOG Practice Bulletin No. 107: Induction of labor. Obstet Gynecol 2009, 114(2 Pt 1):386-397.

3. O'Rourke PT, Girardi GJ, Balaskas TN, et al: Implementation of a SystemWide Policy for Labor Induction. Am J Maternal-Child Nursing 2011, 36(5):305-311.

4. Committee Opinion No. 561: Nonmedically Indicated Early-Term Deliveries. Obstet Gynecol 2013, 121(4):911-915, 910.1097/1001. AOG.0000428649.0000457622.a0000428647.

5. Commission J: Measure Set: Prenatal Care (PC) - Set Measure ID: PC-01. Joint Commission National Quality Measures - (v2013A1) 2013 [http://manual. jointcommission.org/releases/TJC2013A/MIF0166.html].

6. Ehrenthal DB, Hoffman MK, Jiang XZ, Ostrum G: Neonatal Outcomes After Implementation of Guidelines Limiting Elective Delivery Before 39 Weeks of Gestation. Obstet Gynecol 2011, 118(5):1047-1055.

7. Kopp DM, Tronnes A, Lannon S: Impact of delaying term delivery on stillbirth rate. Am J Obstet Gynecol 2014, 210(1):S38-S39.

8. Boulvain M, Marcoux S, Bureau M, Fortier M, Fraser W: Risks of induction of labour in uncomplicated term pregnancies. Paediatric Perinatal Epi 2001, 15(2):131-138

9. Cammu H, Martens G, Ruyssinck G, Amy JJ: Outcome after elective labor induction in nulliparous women: a matched cohort study. Am J Obstet Gynecol 2002, 186(2):240-244.

10. Hoffmire CA, Chess PR, Ben Saad T, Glantz JC: Elective delivery before 39 weeks: the risk of infant admission to the neonatal intensive care unit. Matern Child Health J 2012, 16(5):1053-1062.

11. Sengupta S, Carrion V, Shelton J, et al: Adverse neonatal outcomes associated with early-term birth. JAMA pediatrics 2013, 167(11):1053-1059.

12. Cheng $Y W$, Nicholson JM, Nakagawa S, Bruckner TA, Washington AE, Caughey AB: Perinatal outcomes in low-risk term pregnancies: Do they differ by week of gestation? Am J Obstet Gynecol 2008, 199(4):370. e371-370.e377

13. Glantz JC: Term labor induction compared with expectant management. Obstet Gynecol 2010, 115(1):70-76.
14. Dublin S, Lydon-Rochelle M, Kaplan RC, Watts DH, Critchlow CW: Materna and neonatal outcomes after induction of labor without an identified indication. Am J Obstet Gynecol 2000, 183(4):986-994.

15. Mclntire DD, Leveno KJ: Neonatal mortality and morbidity rates in late preterm births compared with births at term. Obstet Gynecol 2008, 111(1):35-41.

16. Tita ATN, Lai YL, Landon MB, et al: Timing of Elective Repeat Cesarean Delivery at Term and Maternal Perioperative Outcomes. Obstet Gynecol 2011, 117(2):280-286

17. Hansen AK, Wisborg K, Uldbjerg N, Henriksen TB: Risk of respiratory morbidity in term infants delivered by elective caesarean section: cohort study. BMJ 2008, 336(7635):85-87.

18. Grimes DA, Schulz KF: False alarms and pseudo-epidemics: the limitations of observational epidemiology. Obstet Gynecol 2012, 120(4):920-927.

19. Stock SJ, Ferguson E, Duffy A, Ford I, Chalmers J, Norman JE: Outcomes of elective induction of labour compared with expectant management: population based study. BMJ 2012, 344.

20. Darney BG, Snowden JM, Cheng YW, Jacob L, Nicholson JM, et al: Elective Induction of Labor at Term Compared with Expectant Management: Maternal and Neonatal Outcomes. Obstet Gynecol 2013, 122(4):761-769.

21. Mishanina E, Rogozinska E, Thatthi T, Uddin-Khan R, Khan KS, Meads C: Use of labour induction and risk of cesarean delivery: a systematic review and meta-analysis. CMAJ 2014, DOI:10.1503/cmaj.130925.

22. ACOG: Committee Opinion No 579: Definition of term pregnancy. Obstet Gynecol 2013, 122(5):1139-1140.

23. Nicholson JM, Holt M: Will active management of obstetric risk lower $\mathrm{C} / \mathrm{S}$ rates? Contemoraryp Ob Gyn 2005, 50(9):38-53.

24. Flamm BL, Berwick DM, Kabcenell A: Reducing cesarean section rates safely: lessons from a "breakthrough series" collaborative. Birth 1998, 25(2):117-124

25. Rodriguez-Osorio CA, Dominguez-Cherit G: Medical decision making: paternalism versus patient-centered (autonomous) care. Current opinion in critical care 2008, 14(6):708-713.

26. McCullough LB: The professional medical ethics model of decision making under conditions of clinical uncertainty. Medical Care Research Review: MCRR 2013, 70(1 Suppl):141S-158S.

27. Chaillet N, Dube E, Dugas M, et al: Evidence-based strategies for implementing guidelines in obstetrics - A systematic review. Obstet Gynecol 2006, 108(5):1234-1245

28. Andrews JC, Schunemann HJ, Oxman AD, et al: GRADE guidelines: 15. Going from evidence to recommendation-determinants of a recommendation's direction and strength. J Clin Epidemiol 2013 66(7):726-735

doi:10.1186/1471-2393-15-S1-A9

Cite this article as: Nicholson: The 39-week rule and term stillbirth: beneficence, autonomy, and the ethics of the current restrictions on early-term labor induction in the US. BMC Pregnancy and Childbirth 2015 15(Suppl 1):A9.

\section{Submit your next manuscript to BioMed Central and take full advantage of:}

- Convenient online submission

- Thorough peer review

- No space constraints or color figure charges

- Immediate publication on acceptance

- Inclusion in PubMed, CAS, Scopus and Google Scholar

- Research which is freely available for redistribution

Submit your manuscript at www.biomedcentral.com/submit
Biomed Central 